\title{
L'evolució de la referència als participants en el debat parlamentari en català (1932-2013)
}

\author{
The evolution of the reference to the participants \\ in Catalan parliamentary debate (1932-2013)
}

\begin{abstract}
Neus Nogué Serrano
Universitat de Barcelona.nnogue@ub.edu

Received: 06/05/2018. Accepted: 07/08/2018

Resum: Aquest article presenta sumàriament els primers resultats d'una recerca en curs que té com a objectiu estudiar l'evolució de les estratègies lingüístiques i discursives utilitzades per a la referència als participants en el Parlament de Catalunya en el període 1932-38 (durant la Segona República Espanyola) i en el període que va des de la recuperació de les institucions democràtiques catalanes, el 1980, fins al 2013. L'anàlisi combina els mètodes qualitatius amb els quantitatius i mostra diverses tendències en l'evolució de l'ús de les diferents formes i estratègies. La incorporació dels marcs participatius de Goffman (1981) a l'anàlisi proporciona un conjunt de dades que, un cop descrites i interpretades, permeten respondre d'una manera més precisa als interrogants plantejats que si només s'haguessin analitzat les formes díctiques de persona i els tractaments honorífics. I això és rellevant, no només per als debats parlamentaris, sinó per a qualsevol esdeveniment comunicatiu en què adoptin el rol d'enunciadors més de dos participants.
\end{abstract}

Paraules clau: referència als participants; dixi de persona; cortesia; tractaments; llenguatge parlamentari; llenguatge polític.

\footnotetext{
Abstract: This article presents summarily the first results of a research in progress that aims to study the evolution of the linguistic and discursive strategies used for the reference to participants in the Parliament of Catalonia in the period 1932-38 (during the Spanish Second Republic) and from 1980, the year of the recovery of the Catalan democratic institutions, to 2013. The analysis combines qualitative and quantitative methods and shows several tendencies in the evolution of the use of the different forms and strategies. The incorporation of Goffman (1981)'s participation frameworks to the analysis provides additional data that, once described and interpreted, give a much more accurate answer to the questions set out than the analysis of only person deictic

》 Nogué Serrano, Neus. 2018. “L'evolució de la referència als participants en el debat parlamentari en català (1932-2013)". Quaderns de Filologia: Estudis Lingüístics XXIII: 283-307. doi: 10.7203/qf.23.13532
} 
forms and honorifics. And this is relevant not only for parliamentary debates but also for any other speech event with more than two participants.

Keywords: reference to participants; person deixis; politeness; honorifics; parliamentary language; political language. 


\section{Introducció}

Un simple cop d'ull al Diari de Sessions del Parlament de Catalunya del període 1932-38, durant la Segona República Espanyola, permet veure que entre aquella època $i$ el període actual hi ha diferències considerables en l'estil discursiu que fan servir els diputats. I la primera impressió és que els canvis es poden explicar en termes de formalitat, d'un estil més formal a un altre que ho és menys. Però aquesta impressió, es correspon amb la realitat? I quins són els trets lingüístics en què s'expressa?

Aquest article pretén donar una primera resposta a aquestes preguntes centrant-se en un aspecte concret del discurs parlamentari, i més concretament del debat parlamentari: la referència als participants en aquest esdeveniment comunicatiu.

\subsection{Marc teòric}

Per donar resposta als interrogants plantejats amb aquesta recerca, ha calgut combinar conceptes i categories procedents de diferents disciplines i orientacions teòriques.

En primer lloc, la dixi de persona, a partir del marc establert per Levinson (1983) i dels estudis sobre el català que s'han dut a terme en les darreres dècades (Payrató, 2002; Cuenca, 2004 i 2014; Nogué, 2005, 2008a, 2008b, 2011 i 2015; i De Cock \& Nogué, 2017).

En segon lloc, el sistema de tres graus (tu-vós-vostè) de tractaments del català, a partir de la caracterització de Coromines (1971) i la GIEC, i tenint en compte igualment les observacions de Lacreu (1990), Bassols (2001) i Nogué (2005 i 2008a). Com a forma pròpia de l'esdeveniment de parla estudiat, també s'hi ha inclòs el tractament de (la) Vostra Senyoria / (sa) senyoria.

I finalment, s'incorpora a l'anàlisi la noció de participant i les diferents categories en què es pot descompondre. Tenint en compte precedents com els de Bühler (1934), Jakobson (1960) i Hymes (1974), aquí s'assumeix el marc proposat per Goffman (1981), que resumim tot seguit.

En la producció d'un enunciat o format de producció (production format, en anglès), noció que es pot identificar amb la d'enunciador, Goffman distingeix entre l'animador (qui posa la veu o les mans per 
materialitzar físicament el que es diu), l'autor (qui el codifica lingüísticament) i el responsable (el càrrec o rol des del qual s'assumeix la responsabilitat del que es diu). La categoria gramatical de primera persona -singular o plural- només codifica la referència al responsable, tant quan un participant adopta només aquest component de la producció d'un enunciat com quan n'adopta algun altre, o tots alhora, que és el cas més habitual.

En la recepció d'un enunciat o format de recepció (reception format, en anglès), noció que es pot identificar amb la d'enunciatari, Goffman distingeix entre participants ratificats (acceptats en l'esdeveniment comunicatiu) i no ratificats (no acceptats). Entre els primers, separa els destinataris directes d'un enunciat dels destinataris no interpel-lats; i entre els segons, els oients potencials, percebuts, dels espies, no percebuts.

De totes aquestes distincions, la que resultarà més pertinent per a la nostra anàlisi és la que Goffman estableix entre destinataris directes $\mathrm{i}$ destinataris no interpel·lats, com es veurà més avall. (Per a una caracterització més detallada dels marcs participatius, vegeu Nogué, 2005: cap. 4, i 2008a: cap. 4.)

D'altra banda, aquest estudi s'inscriu en l'àrea de l'anàlisi del discurs polític, i més concretament del discurs parlamentari. Aquest gènere es caracteritza per un conjunt de trets discursius fortament institucionalitzats i per un alt grau de regulació, que es concreta en una estructuració estricta de la durada dels torns de parla i de la manera com es distribueixen entre els participants. Encara més específicament, el debat parlamentari es pot descriure, d'una manera general, com un intercanvi formal protagonitzat per tots els grups parlamentaris que se centra en un tema concret i que és moderat pel president del Parlament. Com a discurs dialògic, el debat parlamentari comparteix característiques amb els altres gèneres en què pren la paraula més d'un participant, però alhora se'n separa a causa dels propòsits comunicatius específics que en són part constitutiva: la negociació de solucions polítiques, l'arribada a acords i la presa de decisions, entre altres. La pluralitat ideològica, a més, fa que les propostes siguin sovint divergents, cosa que garanteix el caràcter competitiu de l'intercanvi i la polarització de les posicions, la lluita dialèctica entre els grups parlamentaris que governen en un moment determinat i els que assumeixen el rol de fer d'oposició parlamentària (per a una caracterització més detallada, vegeu Ilie, 2010). 
Per raons d'espai, aquest text se centra en la descripció dels fenòmens i no pot entrar a fons en les consideracions teòriques que poden suscitar els conceptes i categories implicats en l'anàlisi. Tot i així, tal com es recull i destaca a les conclusions, es fa palès que l'anàlisi de la referència als participants i de la seva evolució històrica fa evident la seva relació estreta amb la gestió de la cortesia, com a imatge dels interlocutors i com a factor clau en el desenvolupament de la interacció mitjançant la negociació conversacional.

\subsection{Metodologia}

Aquest treball consisteix en l'anàlisi tant qualitativa com quantitativa de les dades procedents d'un corpus, dividit en cinc subcorpus, extret del Diari de Sessions del Parlament de Catalunya. El primer subcorpus està format per sis debats d'orientació política (no legislativa) que van tenir lloc en el període 1932-38, durant la Segona República Espanyola. Els altres quatre són el contingut íntegre del debat de política general dels anys següents: 1980 (el primer any després de la recuperació de l'activitat parlamentària, amb Convergència i Unió al Govern), 1993 (activitat parlamentària consolidada, majoria absoluta de Convergència i Unió), 2005 (tripartit d'esquerres al Govern) i 2013 (Convergència i Unió un altre cop al Govern, modificació de l'arc parlamentari amb la incorporació de Ciudadanos i la CUP). El corpus té un total de 531.213 paraules, un 2,2 \% de les quals són en castellà (anys 1980 i 2013). L'anàlisi quantitativa té en compte les ocurrències trobades tant en català com en castellà, però l'anàlisi qualitativa se centra en el català. L'extensió dels subcorpus és variable, amb una mitjana de 106.243 paraules.

El corpus ha estat marcat manualment a partir de les categories descrites en el subapartat anterior, i posteriorment ha estat tractat amb el programa Textstat - Simple Text Analysis Tool, de la Freie Universität Berlin, i amb el programa de tractament estadístic SPSS. Més enllà del fet que, per als quatre subcorpus corresponents al període legislatiu actual, les mostres corresponen a esdeveniments comunicatius complets, els resultats obtinguts en l'anàlisi quantitativa són significatius des d'un punt de vista estadístic ${ }^{1}$.

\footnotetext{
${ }^{1}$ Les abreviacions utilitzades en el text són les següents:

Terminologia lingüística: $\mathrm{SN}=$ sintagma nominal, $\mathrm{SG}=$ singular, $\mathrm{PL}=$ plural, $1 \mathrm{SG}=$ primera persona del singular, $2 \mathrm{SG}=$ segona persona del singular, $3 \mathrm{SG}=$ tercera persona
} 


\section{Anàlisi qualitativa}

En aquest apartat es comentaran els fenòmens relacionats amb la referència als participants que van més enllà de les referències díctiques de persona o participatives (usos prototípics de la 1a i la 2a persona) i que, per aquest motiu, han estat poc tractats fins ara en la bibliografia. En primer lloc, es tractaran les estratègies per a la referència a l'enunciador $(\S 2.1)$; en segon lloc, les estratègies per a la referència als grups en què s'inclou $(\S 2.2)$; en tercer lloc, les estratègies per a la referència a un enunciatari $(\$ 2.3)$; i finalment, les estratègies per a la referència a diversos enunciataris o als grups en què l'enunciador els inclou (§ 2.4).

\subsection{La referència a l'enunciador}

\subsubsection{PL "assembleària"}

En el subcorpus del 2013 s'hi troba un ús particular de la 1PL, que no havia aparegut mai abans: el diputat de la CUP David Fernàndez fa un ús de la $1 \mathrm{SG}$ inferior al de la resta de diputats, en favor de la 1PL. Més enllà de la dada quantitativa, però, l'anàlisi qualitativa de les ocurrències de cada categoria gramatical mostra l'intent de reservar el SG per als enunciats estrictament metadiscursius. El motiu cal buscar-lo en la ideologia del grup que representa Fernàndez (independentista, anticapitalista, ecologista i feminista) $i$, sobretot, en els seus processos de presa de decisions, de tipus assembleari. La preferència pel PL, així, reflecteix lingüísticament el fet que com a diputat Fernàndez parla en nom de l'assemblea, i no en nom seu o d'una hipotètica cúpula dirigent de la formació política. Els exemples següents ho il·lustren ${ }^{2}$.

del singular, $1 \mathrm{PL}=$ primera persona del plural, $2 \mathrm{PL}=$ segona persona del plural, $3 \mathrm{PL}=$ tercera persona del plural.

Partits polítics, coalicions i grups parlamentaris: C's $=$ Ciudadanos, CUP $=$ Candidatura d'Unitat Popular, ERC = Esquerra Republicana de Catalunya, $\mathrm{CiU}=$ Convergència $\mathrm{i}$ Unió, GA = Grup Andalusista, IC = Iniciativa per Catalunya, Lliga = Lliga Regionalista, PSC-PSOE $=$ Partit dels Socialistes de Catalunya, PSUC $=$ Partit Socialista Unificat de Catalunya, USC = Unió Socialista de Catalunya.

${ }^{2}$ Per identificar els exemples, s'indica entre parèntesis el cognom o els cognoms amb què és conegut l'enunciador, seguit de l'abreujament corresponent al seu partit o coalició (vegeu nota 1) i de l'any en què es va emetre l'enunciat. En alguns casos, en lloc 
(1) a. Provarem de dir-ho tot sense deixar-nos res en nom de la CUP.

b. Permetin-nos també un bescanvi del llenguatge d'aquestes dues realitats.

(2) a. No entenc la meva lletra...

b. Acabo, em giro, i aquí hi ha un talonari de suport a la vaga indefinida $[\ldots]$ dels docents a les Illes Balears.

(3) I, després, conec experiències, coneixem experiències de la CUP, sobretot, arrelades al territori i a les comarques.

(Fernàndez, CUP, 2013)

A (1a) hi trobem l'ús de la 1PL en un enunciat que fa explícit el recurs comentat més amunt $\mathrm{i}$ a (1b) en un altre que transmet, efectivament, el punt de vista de la CUP; a (2) l'ús de la 1 SG permet a l'enunciador gestionar el seu propi discurs; i finalment, a (3) s'hi pot veure un cas de rectificació sobre la marxa. En tots els casos la 1PL marca la posició del locutor alhora que construeix i gestiona el discurs en el si de la interacció.

\subsection{2. $3 \mathrm{SG}$ amb SN ple}

La 3SG permet a l'enunciador fer referència a ell mateix per mitjà de diverses estratègies (menda, servidor - a...; vegeu Nogué, 2005: 339343; Nogué, 2008a: 209-212). En el llenguatge parlamentari, fent ús d'un SN ple, és una estratègia indirecta de referència i una marca de formalitat, $\mathrm{i}$ alhora permet un cert distanciament respecte a un mateix per posar l'èmfasi en el càrrec que s'ocupa, com es pot veure en els exemples. A l'exemple (4b), a més, per mitjà del demostratiu es conserva el procediment de referència díctica.

(4) a. La Presidència no necessita, agraint-ho molt, cap consell. (Companys, president del Parlament, 1932)

b. en aquesta tasca tindran sempre, si la volen, la col·laboració d'aquest Diputat. (Benet, diputat no adscrit, 1980)

c. El president no ha perdut la confiança en el seu Govern. (Maragall, president de la Generalitat, 2005)

del partit se cita el càrrec (president de la Generalitat, president(a) del Parlament, conseller primer), perquè s'ha considerat que facilita més la comprensió de l'exemple. 
Aquest recurs es troba sobretot en el període 1932-38, seguit de l'any 1980, en què es pot interpretar que s'ha volgut recuperar en algun aspecte la tradició estilística prèvia al trencament provocat pel franquisme; l'any 2005 en fa un ús relativament freqüent el president de la Generalitat, Pasqual Maragall, cosa que explica el repunt que significa aquest any entre el 1993 i el 2013, en què es fa un ús molt reduït d'aquesta estratègia. Sembla, doncs, que la tendència actual és reservar-lo per a ocasions en què es vol obtenir un efecte de distanciament també posar èmfasi en el càrrec, $i$ que cada vegada es fa servir menys només com a marca de formalitat. Els exemples fan evident que l'anàlisi de la referència als participants (i de la cortesia en conjunt) és necessàriament deutora del marc sociocultural i històric en què es fan servir.

\subsection{La referència als grups en què s'inclou l'enunciador}

\subsubsection{PL amb subjecte SN ple}

La combinació d'un verb en 1PL amb un subjecte constituït per un SN ple també en PL, permet a l'enunciador fer explícit el grup en el qual s'inclou, del qual els enunciataris poden formar part o no.

(5) a. tots els Diputats encara estem pendents de quin és l'íntim pensament de Lliga Catalana. (Lluhí, ERC, 1933)

b. Els catalans hem de poder decidir. (Navarro, PSC-PSOE, 2013)

Aquesta estructura, de la qual es troben exemples tot al llarg del nostre corpus, és habitual també en altres registres (Nogué, 2005: 308-310; 2008a: 184-186 i 2015: 224). El català la comparteix amb el castellà i l'occità (De Cock i Nogué, 2017: 108), mentre que altres llengües, com ara l'anglès o l'italià, necessiten un pronom 1PL dins el SN que fa de subjecte (We Italians are very friendly, Noi italiani siamo molto gentili). També es pot trobar en 2PL: Els catalans heu de poder decidir (Nogué, 2005: 308-310; i 2008a: 184-186).

D'altra banda, en el discurs polític i sindical aquesta estructura ha adoptat recentment una variant específica, en què el SN ple que fa de subjecte està en SG i habitualment té com a referent el nom del partit polític en què s'inclou l'enunciador. En el nostre corpus, la primera ocurrència d'aquesta estructura la trobem el 1993 (6a) $i$, tot i que no hi és gaire freqüent, també alguna altra vegada, com a (6b). 
(6) a. Iniciativa per Catalunya hem elaborat [...] un document, amb quaranta o cinquanta mesures. (Saura, IC, 1993)

b. la CUP també faríem els mateixos quatre blocs però canviant-ne els títols. (Fernàndez, CUP, 2013)

Cal observar que en aquesta variant a la discordança de persona entre el SN nominal i el verb s'hi ha afegit la de nombre.

\subsubsection{SG amb SN ple}

L'ús d'un SN ple en SG permet fer referència als grups en què s'inclou l'enunciador. En aquest cas, es tracta de noms col-lectius, que en el nostre corpus solen ser noms de partits, de grups parlamentaris, el conjunt del Parlament, el Govern, la majoria o alguna minoria parlamentària.

(7) a. per a concretar d'una manera ja més ferma el punt de vista del Govern, he de dir que aquest Govern us exposarà l'obra que pensa. (Lluhí, conseller primer, 1932)

b. el 80 per cent del Parlament té clar que no podem mantenir l'statu quo actual. (Mas, president de la Generalitat, 2013)

En un exemple com el de (7a), l'ús del demostratiu preserva la referència díctica $\mathrm{i}$ fa que la inclusió de l'enunciador en la referència sigui explícita; a (7b), en canvi, només per mitjà d'una inferència interpretem que l'enunciador s'inclou en el col·lectiu que esmenta, i l'efecte obtingut és de distanciament. Quan el col·lectiu s'expressa per mitjà d'un SN en PL, l'enunciador pot optar per l'estructura que hem vist a $\S$ 2.1.2, en què la inclusió en el col·lectiu és explícita, o per l'estructura que veurem tot seguit.

\subsubsection{PL amb SN ple}

Un SN ple en PL també permet fer referència als grups en què s'inclou l'enunciador. En contraposició amb l'estratègia de $\S 2.1 .2$, en aquest cas la conceptualització, i l'efecte obtingut, és de distanciament en relació amb el grup i amb la pròpia pertinença, com es fa evident en els exemples següents. 
(8) a. el doctor Martí i Julià i aquest que ara us parla propugnaven per a donar al catalanisme liberalista d'aquella època un gran sentit d'universalitat. (Serra i Moret, USC, 1932)

b. Aquests cent vint diputats i diputades, aquest Parlament, mereixen respecte. (Carod-Rovira, ERC, 2005)

Els enunciadors dels dos exemples de (8) formen part del grup de què parlen, però l'ús de la 3 a persona els permet distanciar-se'n i parlar-ne com si ells no en formessin part.

\subsection{La referència a un enunciatari}

\subsubsection{El tractament de $t u$}

En els debats que formen part del nostre corpus, el tractament de $t u$ no s'utilitza mai per a la referència al destinatari directe. Tots els partits i grups parlamentaris, de cap a cap de l'hemicicle i des del 1932 fins al 2013, segueixen una norma no escrita que regula les referències als participants en els debats parlamentaris i eviten l'ús d'aquesta forma de tractament, que s'allunya de l'alt nivell de formalitat associat amb aquest esdeveniment de parla.

Malgrat això, en els debats del període actual -no pas durant la Segona República- s'hi poden trobar un cert nombre d'ocurrències de la $2 \mathrm{SG}$, que corresponen als usos següents:

a) En determinats marcadors discursius (sovint, però no sempre, en fragments de discurs reportat directe), sobretot mira i escolta('m) (i algun cas de espera).

(9) diu que el que ha passat ara ja passava, doncs, en altres èpoques i que no passa res, vaja, que, escolta, que als governs anteriors els passava exactament el mateix. (Mas, CiU, 2005)

b) En citacions en discurs directe que reprodueixen fragments de conversa entre l'enunciador i una altra persona, pública (bàsicament, altres polítics) o anònima. És significatiu que, fins i tot quan l'interlocutor és un altre polític i el tema de conversa és la política, només el fet de sortir de l'escenari parlamentari per mitjà del discurs reportat directe ja 
facilita el pas al tractament de $t u$ : a (10), Carlos Solchaga era el ministre d'Economia i Hisenda del Govern espanyol.

(10) l'any passat vàrem dir a en Solchaga: «El plantejament que tu fas és irreal, és voluntarista». (Pujol, president de la Generalitat, 1993)

c) Amb valor genèric, que no deixa de ser una referència atenuada a l'enunciador mateix (Nogué, 2005: 331-336 i 2008a: 203-207). Aquest ús, que es pot considerar vinculat més aviat als registres informals (Nogué, 2008b: 213), apareix per primera vegada en el nostre corpus el 1993, amb una sola ocurrència; reapareix el 2005, amb dues; i augmenta considerablement el 2013, en què en fan ús diversos diputats, i d'una manera especial Artur Mas (CiU, president de la Generalitat).

(11) de què serveix tenir el 50 per cent de participació en l'IVA, si després resulta que quan incrementes els IVA tu no tens cap rendiment addicional. (Mas, president de la Generalitat, 2013)

Molt probablement, doncs, més enllà de la referència als participants, l'ús genèric de la $2 \mathrm{SG}$ es pot considerar un marcador d'informalitat en l'evolució estilística del discurs parlamentari.

\subsubsection{El tractament de vós}

Dels tres graus que té el sistema de tractaments del català (tu-vós-vostè), el de vós és el que s'usa d'una manera regular en el període 1932-38. El fan servir tant els presidents de la Generalitat i del Parlament com els diputats dels diferents partits.

(12) És això justament el que jo us demanava i em plau que ho veieu així. (Martínez Domingo, Lliga, 1933)

Aquesta forma de tractament alterna en aquest mateix període amb la fórmula (la) Vostra Senyoria, que en procedeix i que s'hi usa amb força més freqüència: 40 ocurrències de vós per 200 de (la) Vostra Senyoria (vegeu-ne una descripció més detallada a Nogué, 2005: 361-364 i 2008a: 226-229).

En el període actual, només trobem alguna ocurrència d'aquest tractament el 1980 (concretament, 6), i el 1993 d'una manera sistemàtica en 
el discurs d'un sol diputat, Àngel Colom (ERC). Aquest últim és un cas del que en estadística s'anomena valor atípic o outlier.

\subsubsection{El tractament de vostè}

Partint d'una aparició només esporàdica durant el període 1932-38, el tractament de vostè ha passat a ser cada vegada més utilitzat com a estratègia de referència al destinatari directe dels enunciats del debat parlamentari. Procedent de vostra mercè, i per tant del tractament de vós, en funció de subjecte la concordança s'estableix en $3 a$ persona. Malgrat els intents que s'han fet de revitalitzar el tractament de vós, és l'estratègia més freqüent avui per a les interaccions públiques i formals, i així es reflecteix al Parlament en l'ús de tots els partits, incloent-hi l'esquerra anticapitalista, com es pot veure als exemples (vegeu-ne una descripció més detallada a Nogué, 2005: 367-371 i 2008a: 231-234).

(13) a. Senyor Macià Alavedra, no ens ofenguem, vostè està a la dreta i jo a l'esquerra. Si vostè es considera de dreta popular, jo em considero d'esquerra popular. (Gutiérrez Díaz, PSUC, 1980)

b. Vostè parlava de colideratge, una tesi que surt molt del marquès d'ESADE, si em permet dir-ho així. (Fernàndez, CUP, 2013)

Aquest ús del tractament de vostè en el debat parlamentari és del tot coherent amb el seu ús com a marcador de formalitat en altres contextos comunicatius de la societat catalana actual.

\subsection{4. (La) Vostra Senyoria}

Com ja s'ha dit, el tractament de (la) Vostra Senyoria és el més freqüent en el subcorpus de la Segona República per a la referència al destinatari directe. El Diari de Sessions del Parlament el representa normalment per mitjà de l'abreviació $V$. $S$.

(14) Senyor Lluhí: en l'article 14.è de l'Estatut s'estableix, d'una manera precisa i categòrica, una cosa que també ha reconegut V. S. (Ventosa i Calvell, Lliga, 1932)

Procedent, com el de vostè, del tractament de vós, en posició de subjecte concorda amb el verb, com aquell, en tercera persona. Actualment 
està fortament relacionat $\mathrm{amb}$ un esdeveniment de parla concret: el judici (De Cock \& Nogué, 2017: 116). En el corpus del període actual no hi trobem cap ocurrència en SG d'aquesta forma de tractament.

\subsubsection{SG amb SN ple}

Quan analitzem l'ús d'un SN ple per a la referència a l'enunciatari, resulta del tot rellevant la distinció de Goffman entre destinatari directe $\mathrm{i}$ destinatari no interpel·lat (vegeu més amunt, $\S 1.1$ ).

Per a la referència al destinatari directe, aquest recurs s'utilitza amb propòsits similars als que trobem quan es fa servir per a la referència a l'enunciador: com a estratègia indirecta, és una marca de formalitat $i$ una manera de marcar distància, $i$ sovint de posar èmfasi en el càrrec, no en la identitat de l'interlocutor.

(15) a. Però recordi el senyor Ventosa que... (Lluhí, ERC, 1933)

b. El Diputat senyor Benet vol replicar la intervenció? (Barrera, president del Parlament, 1980)

Trobem exemples d'aquest ús sobretot en el subcorpus de la Segona República i en el debat del 1980; en el del 1993 es redueix molt; i és inexistent en els dos últims (2005 i 2013). Cal dir també que, fora dels enunciats interrogatius i imperatius, sovint la frontera entre l'ús d'aquesta estructura per a la referència al destinatari directe i per a la referència al destinatari no interpel·lat, no és fàcil d'establir.

La 3SG es pot considerar l'estratègia no marcada per a la referència al destinatari no interpel·lat: com que la 2a persona només gramaticalitza la referència al destinatari directe, no pot ser utilitzada per a aquest segon tipus de destinatari ratificat, i el català, com altres llengües, recorre a la 3 a persona per fer-hi referència.

(16) a. Té la paraula el molt honorable senyor Pasqual Maragall. (Benach, president del Parlament, 2005)

b. Resta elegit President de la Cambra el Diputat senyor Josep Irla i Bosc. (Serra i Húnter, president interí del Parlament, 1938)

c. a això el senyor Junqueras potser no hi ha fet referència, però jo també ho vull esmentar. (Mas, president de la Generalitat, 2013) 
És per aquest motiu que trobem aquesta estratègia en tots els debats del nostre corpus (i de fet, en tots els gèneres $\mathrm{i}$ registres interactius en què hi ha més de dos participants; vegeu Nogué, 2005: 371-377 i 2008a: 234-238). Cal tenir en compte que l'exemple (16a) il·lustra una fórmula fixada per cedir el torn de parla, utilitzada tot al llarg del nostre corpus pel president del Parlament en la seva funció de moderador del debat. Això assegura, doncs, un cert nombre d'ocurrències d'aquesta estratè-gia en tots els debats. Cal dir que la trobem amb més freqüència en els de la Segona República i amb tendència a disminuir en el període actual, malgrat un repunt el 2005. En aquest cas, les diferències en el nombre d'ocurrències, s'han d'atribuir, molt probablement, a una redistribució global de les estratègies de referència als participants en el debat parlamentari, com es podrà veure més endavant, en l'anàlisi quantitativa del corpus $(\S 3)$.

\subsubsection{Vocatius ${ }^{3}$}

L'ús d'un vocatiu per a la referència a un únic destinatari directe és una estratègia que s'utilitza relativament poc en el subcorpus de la Segona República: hi ha menys tipus de vocatius i també és menor el nombre d'ocurrències, si ho comparem amb el període actual. Aquesta evolució s'ha d'atribuir al fet que el vocatiu és una manera directa d'adreçar-se a l'interlocutor; per aquest motiu, en aquella època es preferien formes de referència més indirectes, més corteses i més formals. Amb el pas del temps es detecta un augment tant de la diversitat de formes utilitzades com de les ocurrències totals.

Les principals estructures que trobem en els vocatius en SG del nostre corpus són les següents:

1. $\operatorname{Senyor}(a)+$ CÀRREC. Sobretot, senyor $(a)$ president $(a)$; però també senyor(a) diputat -ada, senyor (a) conseller $(a)$, senyor secretari, senyor portaveu...

\footnotetext{
${ }^{3}$ L'estudi detallat dels vocatius en el debat parlamentari requereix entrar en matisos que van molt més enllà de l'abast d'aquest article. Tant en aquest apartat com a $§ 2.4 .6$, em limitaré a mostrar les tendències més generals que es poden trobar en el corpus analitzat. D'altra banda, en els exemples no tinc en compte la grafia amb majúscula inical (predominant en els dos primers subcorpus) o amb minúscula inicial (predominant a partir del 1993).
} 
2. Senyor $(a)+\operatorname{COGNOM}(\mathrm{S})$. En són exemples: senyor Lluhí, senyor Gutiérrez Díaz, senyor Mas, senyora Rovira.

3. President(a). Apareix per primer cop el 1993, però usat per un sol diputat (Colom, ERC); el 2005 i el 2013 ja l'usen diversos diputats. La simplificació en l'estructura, sense tractament i només amb expressió del càrrec, la converteix en una de les marques més clares d'informalit-zació del discurs parlamentari.

4. (Molt) honorable (senyor $(a))$ president $(a)$. El tractament honorífic de màxima formalitat és usat amb diverses variants: Molt honora-ble senyor (a) president(a), honorable senyor president, honorable president...

\subsection{La referència a diversos enunciataris o al grup de l'enunciatari}

\subsubsection{Vosaltres}

En el sistema de tractaments de tres graus que té el català, la forma vosaltres correspon tant al PL de tu com al PL de vós. En el subcorpus corresponent a la Segona República, és usada amb el segon d'aquests valors, i a diferència del que vèiem per a la referència a un sol destinatari directe, és la forma preferida pels diputats (748 ocurrències, per a 43 en el cas del tractament de (les) Vostres Senyories).

(17) Honorables Diputats: La vostra presència ací, com a representants que sou del poble i membres d'aquestes Corts catalanes. (Macià, president de la Generalitat, 1932)

En el període actual, se'n fa un ús esporàdic, amb tendència a créixer. Donada l'absència del tractament de vós, s'ha d'interpretar com a PL del tractament de $t u$ per a la referència al conjunt dels diputats o a una part (18). A diferència de la $2 \mathrm{SG}$, sembla que el sol fet de tenir com a referent un col·lectiu i no un destinatari directe únic, facilita la irrupció d'aquesta forma de tractament en un àmbit amb predomini aclaparador del tractament de vostès, com veurem més avall (§ 2.4.2), que s'ha d'interpretar en relació amb la pèrdua progressiva de marques de formalitat que trobem en el discurs parlamentari.

(18) les nostres ciutats metropolitanes, de les quals alguns de vosaltres sou o heu estat alcaldes. (Junqueras, ERC, 2013) 
També trobem aquest tractament en algun cas, com passava amb el tractament de $t u$ en SG, en fragments de discurs reportat directe (19).

(19) els ho hem de dir, haurem de dir amb coratge: «Escolteu, aquí no n'hi haurà mai, de regs. Per tant, feu el que vulgueu [...]». (Pujol, president de la Generalitat, 1980)

\subsubsection{Vostès}

Paral·lelament a la forma corresponent en SG, el tractament de vostès el trobem només esporàdicament en el subcorpus de la Segona República, $i$ en canvi, amb una freqüència creixent, en els subcorpus corresponents al període actual, en tots els partits de l'arc parlamentari.

(20) Aquest Parlament s'ha de reactivar, i vostès, més que cap altre grup polític, tenen la responsabilitat de reactivar la vida d'aquest Parlament. Moltes gràcies per la seva atenció. (Obiols, PSC-PSOE, 1993)

L'exemple anterior mostra, a més, com aquest tractament, de la mateixa manera que altres formes de referència al destinatari directe, pot tenir referents diferents en enunciats consecutius: en el primer, l'enunciador es refereix al Govern i al seu grup parlamentari (CiU), i en el segon, al conjunt dels diputats del Parlament ${ }^{4}$.

\subsection{3. (Les) Vostres Senyories}

Com en el SG corresponent, el tractament (les) Vostres Senyories el trobem utilitzat d'una manera sistemàtica en el subcorpus de la Segona República, però menys sovint que el tractament de vosaltres, com hem vist a $\S 2.4 .1$.

(21) El 12 d'abril les VV. SS. es quedaven a casa seva. (Lluhí, ERC, 1933)

A diferència de (la) Vostra Senyoria, però, el PL també el trobem, encara que molt esporàdicament, només amb dues ocurrències (una en català i una altra en castellà), en el subcorpus del 1980, ben bé com una

\footnotetext{
${ }^{4}$ Una anàlisi multimodal de fragments com aquest, que inclogués la gestualitat, la posició corporal i sobretot la mirada, permetria corroborar-ho amb més precisió.
} 
resta de la tradició anterior, abandonada en el període actual. D'una manera significativa, les dues ocurrències les trobem en la variant ses senyories / sus señorías; és a dir, formades, no a partir del tractament de vós, sinó a partir del tractament de vostè.

(22) a. em limitaré [...] per no cansar ses senyories, a mencionar d'una manera bastant puntual cadascun dels punts. (Vicens, ERC, 1980)

b. a nosotros nos interesa todo, pero sus señorías saben que, de forma especial, lo que hace referencia a la política cultural y social. (Acosta, GA, 1980)

\subsubsection{SG amb SN ple}

L'ús d'un SN ple en SG, amb un nom col·lectiu com a nucli (partit, grup parlamentari, ple del Parlament, Govern, la majoria parlamentària, una minoria...), permet fer referència als diversos grups de participants en el debat parlamentari.

Cal distingir entre els casos en què es fa referència a un col-lectiu com a destinatari directe de l'enunciat (23), i els casos en què l'enunciador s'adreça al conjunt dels diputats i per mitjà d'aquesta estratègia només fa referència a una part, que es constitueixen com a destinataris no interpel $\cdot$ lats (24).

(23) a. Ho accepta així la minoria regionalista? (Companys, president del Parlament, 1932)

b. EI Grup Socialista no hi veuria inconvenient? (Barrera, president del Parlament, 1980)

(24) a. El Govern no vol rectificar. (Ventosa, Lliga, 1933)

b. El Govern sap que té el suport de la majoria d'aquesta cambra. (Bargalló, conseller primer, 2005)

La primera estratègia és utilitzada 15 vegades en el subcorpus de la Segona República, i 10 l'any 1980. El distanciament que provoca l'ús de la 3 a persona, en comparació amb les altres estratègies de referència a l'enunciatari, i l'evolució cap a la preferència per formes més directes, expliquen aquest ús tan poc freqüent i l'absència absoluta d'ocurrències des del 1993. 
La segona estratègia, com ja hem vist en relació amb un enunciatari únic, és la pròpia d'aquesta mena de referència. És per aquest motiu que el nombre d'ocurrències és molt més alt en tot el corpus, encara que s'hi observa una certa tendència a la disminució.

\subsubsection{PL amb SN ple}

En paral·lel amb l'estratègia anterior, també trobem SN en 3PL per a la referència a l'enunciatari, tant per a la referència a un grup de destinataris directes (25) com per a la referència a un grup de destinataris no interpel·lats (26).

(25) a. Resten suspeses les sessions. Per a la vinent, els senyors Diputats seran advertits a domicili. (Companys, president del Parlament, 1932)

b. Als altres portaveus els va bé aquesta agrupació? (Xicoy, president del Parlament, 1993)

(26) a. aquest drama que es viu en aquests pobles, que els Diputats de la demarcació de Lleida coneixen perfectament. (Pujol, president de la Generalitat, 1980)

b. Prossegueix el debat amb les intervencions dels representants dels grups parlamentaris. (Benach, president del Parlament, 2005)

L'exemple (25a) és un cas clar d'aquest ús: en el context del debat parlamentari, qualsevol SN que signifiqui 'tots els diputats' té com a referent o bé el conjunt dels enunciataris, als quals l'enunciador s'adreça directament, com en aquest cas, o bé el conjunt de participants, grup en el qual també s'inclouria l'enunciador.

Les dades quantitatives segueixen un patró similar al de l'estratègia anterior, però amb xifres globals menors: un nombre reduït d'ocurrències per al primer tipus, sense cap cas ni el 2005 ni el 2013, i un nombre més gran per al segon, amb tendència a la disminució.

\subsubsection{Vocatius}

A diferència del que vèiem a $\S 2.3 .6$, en el subcorpus de la Segona República és on més ocurrències trobem de vocatius per a la referència a diversos destinataris directes. Probablement, això és degut al fet que la 
referència a un col·lectiu els fa una estratègia més indirecta $i$, per tant, més acceptable en aquell context $i$ en aquella època. L'evolució posterior s'ha d'atribuir a una redistribució de les estratègies de referència que es podrà percebre amb més claredat en l'anàlisi quantitativa global de les dades.

Les principals estructures que trobem en els vocatius en PL del nostre corpus són les següents:

1. Senyores $i$ senyors diputats. El trobem des del 1980, en tots els subcorpus del període actual; per tant, des que hi ha homes i dones al Parlament. És, probablement, un dels primers desdoblaments de masculí i femení més o menys sistemàtics que trobem en català.

2. Senyors diputats. És, de lluny, el vocatiu en PL més utilitzat durant la Segona República, quan al Parlament només hi havia homes.

3. Senyores diputades i senyors diputats (o senyors diputats i senyores diputades; o senyores diputades, senyors diputats; o senyors diputats, senyores diputades). Com a forma de desdoblament més complexa, també la trobem, però menys sovint, en tot el període actual.

4. Diputats i diputades (o diputades i diputats; o diputades, diputats; o diputats, diputades). Molt menys freqüent que les anteriors, és un indici de tendència a la simplificació de les estructures sintàctiques dels vocatius propis del debat parlamentari (com ja hem vist amb president $(a)$, a $§ 2.3 .6)$; simplificació que va aparellada amb un grau menor de formalitat.

\section{Anàlisi quantitativa}

En aquest apartat es presenten sumàriament les dades quantitatives globals d'aquest estudi. A la taula $1 \mathrm{~s}$ 'hi poden trobar els resultats, desglossats i globals, sense tenir en compte les estratègies en 3a persona, i a la taula 2, els resultats corresponents a la 3 a persona i la modificació dels resultats globals que provoquen. 


\begin{tabular}{|l|r|r|r|r|r|}
\hline & $1932-38$ & 1980 & 1993 & 2005 & \multicolumn{1}{c|}{2013} \\
\hline 1 a sg. & 2.129 & 2.070 & 2.119 & 2.008 & 1.839 \\
\hline 1 la pl. & 2.377 & 2.965 & 2.754 & 2.650 & 3.067 \\
\hline 2a sg. & 0 & 10 & 9 & 26 & 23 \\
\hline Tractament de vós & 40 & 4 & 366 & 0 & 0 \\
\hline Tractament de vostè & 4 & 312 & 858 & 1.317 & 1.770 \\
\hline Vostra Senyoria & 200 & 0 & 0 & 0 & 0 \\
\hline Vocatius sg. & 62 & 237 & 260 & 232 & 348 \\
\hline 2a pl. (tu i vós) & 748 & 32 & 42 & 18 & 48 \\
\hline Tractament de vostès & 4 & 401 & 692 & 1.176 & 1.243 \\
\hline Vostres Senyories & 43 & 2 & 0 & 0 & 0 \\
\hline Vocatius pl. & 92 & 70 & 63 & 67 & 57 \\
\hline Total & 5.699 & 6.103 & 7.163 & 7.494 & 8.365 \\
\hline
\end{tabular}

Taula 1. Dades globals sense 3a persona (per 100.000 paraules)

\begin{tabular}{|l|r|r|r|r|r|}
\hline & $\begin{array}{c}1932- \\
38\end{array}$ & 1980 & 1993 & 2005 & 2013 \\
\hline 3a sg. $\rightarrow$ referència a l'enunciador & 71 & 48 & 8 & 36 & 9 \\
\hline 3a sg. $\rightarrow$ ref. al grup de l'enunciador & 782 & 348 & 268 & 412 & 248 \\
\hline 3a pl. $\rightarrow$ ref. al grup de l'enunciador & 47 & 20 & 16 & 25 & 6 \\
\hline 3a sg. $\rightarrow$ ref. al destinatari directe & 15 & 19 & 5 & 0 & 0 \\
\hline $\begin{array}{l}\text { 3a sg. } \rightarrow \text { ref. a un dest. no } \\
\text { interpel·lats }\end{array}$ & 1.279 & 986 & 404 & 724 & 194 \\
\hline $\begin{array}{l}\text { 3a sg. } \rightarrow \text { ref. a un grup de destinata- } \\
\text { ris directes }\end{array}$ & 15 & 2 & 0 & 0 & 0 \\
\hline $\begin{array}{l}\text { 3a sg. } \rightarrow \text { ref. a un grup de dest. no } \\
\text { interpel·lats }\end{array}$ & 488 & 321 & 274 & 430 & 154 \\
\hline $\begin{array}{l}\text { 3a pl. } \rightarrow \text { ref. a un grup de destinata- } \\
\text { ris directes }\end{array}$ & 3 & 2 & 3 & 0 & 0 \\
\hline $\begin{array}{l}\text { 3a pl. } \rightarrow \text { ref. a un grup de dest. no } \\
\text { interpel·lat }\end{array}$ & 244 & 321 & 49 & 149 & 27 \\
\hline \begin{tabular}{l} 
Total \\
\hline
\end{tabular} & 8.843 & 8.170 & 8.190 & 9.270 & 9.003 \\
\hline
\end{tabular}

Taula 2. 3a persona i suma total (per 100.000 paraules) 
Les dades globals corresponents a la referència a l'enunciador i als grups en què s'inclou mostren les tendències següents:

1. En termes relatius, un augment de la preferència per la inclusió en un grup en detriment de les referències individuals a un mateix.

2. L'augment gradual de les formes díctiques de referència (en 1a persona, SG o PL), les més directes i menys corteses, en detriment de les de 3a persona, menys directes i més corteses.

3. Malgrat la tendència anterior, l'estratègia de $3 a$ persona que es redueix menys és el SG per referir-se al propi grup: el partit, el grup parlamentari o el Govern, principalment.

Pel que fa a la referència a l'enunciatari, cal distingir entre la referèn-cia al destinatari directe $\mathrm{i}$ la referència al destinatari no interpel lat.

En la referència al destinatari directe s'hi observen les tendències següents:

1. La pèrdua absoluta en el període actual del tractament de vós, que només s'usa d'una manera sistemàtica durant la Segona República.

2. La pèrdua absoluta en el període actual del tractament de (la) Vostra Senyoria, que només s'usa igualment d'una manera sistemàtica durant la Segona República, tant en les referències individuals com en les col-lectives.

3. La pèrdua absoluta de les estratègies de 3a persona en els dos últims subcorpus, el del $2005 \mathrm{i}$ el del 2013. S'havien usat durant la Segona República i se'n troba encara alguna ocurrència el 1980 i el 1993. La preferència per formes més directes i menys corteses de referència és clara.

4. L'ús sistemàtic del tractament de vostè en el període actual, amb un clar augment sostingut, tant en les referències individuals com en les col·lectives.

5. L'augment sostingut del nombre de vocatius referits a un sol interlocutor. Juntament amb la introducció en els últims anys de formes de vocatiu més simples que hem vist a $\S 2.3 .6$ i a $\S 2.4 .6$, aquest augment mostra un cop més una preferència creixent per formes més directes i menys corteses de referència. 
6. La reducció del nombre de vocatius referits a grups de participants, que queda compensat per l'augment del tractament de vostè que acabem de veure a 4.

En la referència al destinatari no interpel-lat s'hi observen les tendències següents:

1. La reducció global de les referències d'aquesta mena. Sembla que els parlamentaris prefereixen cada vegada més conceptualitzar l'enunciatari, que és sovint l'adversari polític, com a destinatari directe dels seus enunciats, en detriment de la referència directa al conjunt dels diputats, que comporta la conceptualització de l'adversari com a destinatari no interpel·lat $\mathrm{i}$, per tant, l'adopció d'una estratègia indirecta de referència.

2. Dintre d'aquesta tendència general, una reducció relativa menor en el cas de la referència a col·lectius per mitjà d'un SN en SG: partits polítics, grups parlamentaris, el Govern...

3. Una reducció també menor en el cas de la referència a un sol destinatari no interpel·lat. Hi té a veure el manteniment al llarg de tot el corpus de la fórmula de cessió de torn utilitzada pel president del Parlament Té la paraula el diputat / la diputada...

Finalment, la comparació de les xifres globals de les dues taules mostra d'una manera clara com la incorporació de les estratègies de 3 a persona per a la referència als participants en proporciona una visió diferent i més ajustada a la realitat que es vol descriure i explicar. A diferència de l'augment sostingut global que suggeria la taula 1, aquesta incorporació mostra una tendència a l'augment molt més moderada, $\mathrm{i}$ en canvi com les estratègies preferides pels diputats no són les mateixes: per a la referència a l'enunciador, la tendència és cap a la inclusió en grups en detriment de les referències individuals; per a la referència a l'enunciatari, i sobretot al destinatari directe, es va reduint l'ús de les estratègies en 3 a persona, es perden els tractaments de vós i de (la) Vostra Senyoria, i augmenta d'una manera clara el tractament de vostè.

\section{Conclusions}

Tant l'anàlisi qualitativa del corpus com la quantitativa permeten concloure que la dixi de persona estricta (1a i 2 a persona, incloent-hi els 
tractaments) resulta insuficient per explicar la referència als participants, i que la combinació amb els marcs participatius de Goffman (1981) permet incorporar a l'anàlisi les estratègies de referència als destinataris no interpel-lats, en 3a persona, que s'afegeixen a altres estratègies de referència no prototípiques, també en 3a persona. Els resultats permeten arribar a una descripció i una explicació més acurades i, per tant, assolir els objectius de la recerca. I aquesta primera conclusió general, teòrica i metodològica, va més enllà de l'estudi de la referència als participants en el debat parlamentari i és altament rellevant per a la comprensió de la referència als participants en general.

Pel que fa als resultats concrets de l'estudi, les conclusions es poden resumir en els punts següents:

1. Al llarg de tot el període estudiat, hi ha més varietat d'estratègies per a la referència als diferents tipus d'enunciataris (destinataris directes i destinataris no interpel·lats) i els grups en què s'inclouen que no pas per a la referència a l'enunciador i als grups en què s'inclou.

2. Els vocatius evolucionen, des del punt de vista de l'estructura, de més complexos (Mont Honorable Senyor President) a més simples (president), i des del punt de vista funcional, de més formals a menys formals. La reducció en l'ús de vocatius singulars es pot explicar per l'extensió de l'ús del tractament de vostè, i l'increment en l'ús de vocatius plurals, per la preferència per formes de referència més directes que no pas la 3 a persona.

3. La pèrdua dels tractaments de vós i de (la) Vostra Senyoria (en SG i en PL), i la reducció de l'ús de les formes de 3a persona, queda compensada per l'extensió del tractament de vostè(s). D'aquesta manera, el nombre total d'ocurrències de formes per a la referència als participants varia molt poc, amb una lleugera tendència al creixement $i$, per tant, a incrementar el grau de personalització del discurs propi del debat parlamentari.

4. Les conclusions anteriors suggereixen que des del període 193238 fins ara ha tingut lloc una important evolució estilística: d'estratègies més indirectes i formals a unes altres de més directes $i$ informals. Aquesta conclusió final és coherent amb processos més amplis que han afectat molts altres registres formals al llarg d'aquest temps i que es poden resumir en un desplaçament pro- 
gressiu cap a la informalitat en el contínuum que va de la solemnitat (o grau màxim de formalitat, no absent en el debat parlamentari) a la col·loquialitat més informal (no esperable i de fet no usual en aquest esdeveniment de parla).

\section{Bibliografia}

Bassols, Margarida. 2001. Les claus de la pragmàtica. Vic: Eumo.

Bühler, Karl. 1934. Sprachtheorie. Stuttgart / New York: Gustav Fisher Verlag. Coromines, Joan. 1971. Lleures i converses d'un filoleg. Barcelona: Club Editor.

Cuenca, M. Josep. 2004. El receptor en el text: el vocatiu. Estudis Romànics 26: 39-64.

Cuenca, M. Josep. 2014. The use of demonstratives and context activation in Catalan parliamentary debate. Discourse Studies. doi: 10.1 $177 / 1461445614546258$.

De Cock, Barbara \& Neus Nogué. 2017. The pragmatics of person reference. A comparative study of Catalan and Spanish parliamentary discourse. Languages in Contrast 17(1): 96-127.

GIEC = Institut d'Estudis Catalans. 2016. Gramàtica de la llengua catalana . Barcelona: Institut d'Estudis Catalans.

Goffman, Erving. 1981. Forms of Talk. Oxford: Basil Blackwell.

Hymes, Dell. 1974. Foundations in Sociolinguistics. An Ethnographic Approach. Philadelphia: University of Pennsylvania Press.

Ilie, Cornelia. 2010. Introduction. A Ilie, Cornelia (ed.) European Parliaments under Scrutiny. Amsterdam / Philadelphia: John Benjamins.

Jakobson, Roman. 1960. Linguistics and poetics. A Sebeok, Thomas A. (ed.) Style in Language. Cambridge, MASS: MIT Press.

Lacreu, Josep. 1990. Manual d'ús de l'estàndard oral. València: Institut de Filologia Valenciana. Universitat de València.

Levinson, Stephen. 1983. Deixis. Pragmatics. Cambridge: Cambridge University Press.

Nogué, Neus. 2005. Dixi de persona i marcs participatius en català (Tesi Doctoral). Departament de Filologia Catalana. Universitat de Barcelona.

Nogué, Neus. 2008a. La dixi de persona en català. Barcelona: Publicacions de l'Abadia de Montserrat.

Nogué, Neus. 2008b. La dixi de persona en el discurs acadèmic oral en català. Caplletra 44: 195-218.

Nogué, Neus. 2011. Person Deixis. A Payrató, Lluís \& Cots, Josep Maria (ed.) The Pragmatics of Catalan. Berlin / Boston: De Gruyter Mouton, 115144. 
L'evolució de la referència als participants en el debat parlamentari... 307

Nogué, Neus. 2015. Catalan. A Jungbluth, Konstanze \& Da Milano, Federica (ed.) Manual of Deixis in Romance Languages. Berlin / Boston: De Gruyter, 206-239.

Payrató, Lluís. 2002. L’enunciació i la modalitat oracional (4a ed.). A Solà, Joan; Lloret, Maria-Rosa; Mascaró, Joan \& Pérez Saldanya, Manuel (dir.) Gramàtica del català contemporani. Barcelona: Empúries, 11491220. 
